\title{
Melatonin directly stimulates the secretion of progesterone by human and bovine granulosa cells in vitro
}

\author{
G. E. Webley and M. R. Luck \\ Institute for Hormone \& Fertility Disorders, Osterstrasse 86, 2000 Hamburg 20, \\ Federal Republic of Germany
}

\begin{abstract}
Summary. Melatonin, at concentrations and periods of exposure reflecting those present during the circadian cycle, was investigated for its influence on steroid production by granulosa cells cultured in serum-supplemented medium. At high $(200 \mathrm{pg} / \mathrm{ml})$ but not low $(20 \mathrm{pg} / \mathrm{ml})$ physiological concentrations, melatonin significantly stimulated progesterone production by human granulosa cells. This response was independent of the overall level of cell activity and was seen under the different culture conditions associated with different culture media. Exposure to melatonin for $8 \mathrm{~h}$ significantly stimulated progesterone secretion to a level similar to that achieved under continuous exposure, and the effect was reduced to control levels during subsequent periods in which no melatonin was added. Melatonin had no consistent effect on aromatase activity in the conversion of stored or serum-available androgen to oestradiol.

Melatonin significantly stimulated progesterone production by bovine granulosa cells in vitro, at concentrations similar to those present during the endogenous nocturnal rise $(100-400 \mathrm{pg} / \mathrm{ml})$. This response to physiological conditions by human and bovine cells suggests a role for melatonin in the regulation of progesterone production by the ovary.
\end{abstract}

\section{Introduction}

The influence of the pineal gland on reproductive function has been shown to be mediated by its major hormonal product, melatonin (Cardinali, 1981). The evidence available concerning the site and mechanism of melatonin action is conflicting but suggests that the overall response may be the result of action at central and peripheral sites in the hypothalamic-pituitary-gonadal axis. Early experiments described the distribution of tritiated melatonin; it becomes concentrated in the hypothalamus and mid-brain when administered into the CSF (Cardinali et al., 1973) and enters all tissues, but concentrates only in the ovary, eye and pineal gland when injected systemically (Wurtman et al., 1964). Putative receptors for melatonin have been described in membrane (bovine) and cytosol (rat) fractions of various brain regions (Cardinali et al., 1979; Niles et al., 1979 ) and in the cytosol fraction of hamster and rat gonadal tissue and human ovaries (Cohen et al., 1978).

A direct gonadal response to melatonin has been reported previously, including stimulation of progesterone secretion from human corpus luteum slices treated with pharmacological doses (MacPhee et al., 1975). Melatonin stimulated basal progesterone but not oestradiol secretion in short-term incubation of rat granulosa cells (Fiske et al., 1984) but was inhibitory to testicular androgen production (Peat \& Kinson, 1971; Ellis, 1972; Kano \& Miyachi, 1976). No response to melatonin was seen in bovine luteal cells in short-term incubation (Battista \& Condon, 1986). The physiological relevance of responses observed using pharmacological doses and short periods of exposure is questionable. We have therefore investigated the in-vitro action of melatonin on granulosa cells at concentrations and for periods of exposure which are likely to reflect those occurring during the circadian cycle. 


\section{Materials and Methods}

\section{Cell preparation}

Human. Granulosa cells were taken from preovulatory follicles of women undergoing ovum transfer in the course of an in-vitro fertilization programme. Follicular maturation had been achieved using either clomiphene (Pergotime, Serono, Freiburg, F.R.G.) treatment from Days 3 to 7 of the cycle followed by hMG treatment from Days 8 to 11 or clomiphene from Days 2 to 5 of the cycle and a combination of clomiphene and hMG from Days 5 to 9 . On Day 11 of the cycle the patients received 5000 i.u. hCG and the follicles were aspirated by laparoscopy $36 \mathrm{~h}$ later.

Follicular development was monitored by serum oestradiol concentrations and ultrasonography. Granulosa cells were recovered from follicular fluid and Hams F10 lavages of the follicle, after centrifugation at $250 \mathrm{~g}$ for $10 \mathrm{~min}$. The cells from a single patient were combined in $20-30 \mathrm{ml}$ culture medium (see details given below) and subjected to Percoll (Pharmacia, Uppsala, Sweden) separation to remove red blood cells as follows. The whole cell suspension was divided between two siliconized glass round-bottom tubes, under sterile conditions, and underlayered with $60 \%$ Percoll ( $15 \mathrm{ml} /$ tube). The tubes were centrifuged at $1000 \mathrm{~g}$ for $20 \mathrm{~min}$ (no brake) and the white cell layer, at the medium-Percoll interface, was carefully removed from each tube with a Pasteur pipette. The pooled cells were resuspended in $20 \mathrm{ml}$ medium and centrifuged at $250 \mathrm{~g}$ for $10 \mathrm{~min}$. The medium was removed and the cells washed twice more with $20 \mathrm{ml}$ medium. Before the final centrifugation, the cell suspension was filtered through sterile nylon mesh to remove any clumped cells. A sample of the final preparation was sonicated and used to determine the cell concentration by DNA estimation.

Bovine. Ovaries from cows in the non-luteal phase (no active corpus luteum in either ovary) were obtained from the Hamburg slaughter-house and transported to the laboratory at ambient temperature. Large, follicular-phase, obviously dominant, preovulatory follicles were selected, avoiding those showing morphological signs of atresia (for example, opacity, turbidity, presence of red blood cells in follicular fluid). The selection criteria for bovine follicles used in this laboratory have previously been shown to result in $86 \%$ avoidance of atretic follicles (Jungclas \& Luck, 1986). The follicular fluid was aspirated by syringe and the granulosa cell layer was gently agitated to release the cells into a small quantity of culture medium. The resulting cell suspension and follicular fluid were centrifuged ( $10 \mathrm{~min}, 150 \mathrm{~g}$ ) and the cell pellets combined, before washing twice more in culture medium and sampling for estimation of cell concentration. This procedure resulted in $8-15 \times 10^{6}$ cells per follicle; further details concerning follicle selection and cell preparation have been reported previously (Jungclas \& Luck, 1986).

\section{Cell culture}

The cells were cultured in multiwell plates (Nunclon, Wiesbaden, F.R.G.) at a concentration of $2 \times 10^{5}$ cells. $1 \mathrm{ml} \mathrm{medium}^{-1}$. well ${ }^{-1}$ in replicates of 6 wells per treatment. The culture media that were used during the study were RPMI 1640, Dulbecco's modification of Eagles medium (DMEM) or a 1:1 (v/v) mixture of DMEM and Hams F12 (all from Flow Laboratories, Meckenheim, F.R.G.) each containing 10\% human male serum (human experiments) or fetal calf serum (Gibco, Karlsruhe, F.R.G.; cow experiments). Human male serum was obtained from blood collected at midday when melatonin concentrations are at a minimum. The serum was inactivated at $56^{\circ} \mathrm{C}$ for $30 \mathrm{~min}$ and sterilized by passage through a $0.2 \mu \mathrm{m}$ membrane filter (Schleicher \& Schuell, Dassel, F.R.G.). Melatonin (Sigma, Deisenhofen, F.R.G.) treatments were added in ethanolic solution, with an equivalent quantity of ethanol $(1 \mu \mathrm{l} / \mathrm{ml}$ medium) being added to control wells. Cell attachment occurred within $2-4 \mathrm{~h}$. Cultures were maintained for up to 4 days at $37^{\circ} \mathrm{C}$ in a humidified incubator $\left(95 \%\right.$ air $\left./ 5 \% \mathrm{CO}_{2}\right)$ with changes of media at 8 or $24 \mathrm{~h}$ as indicated for each experiment and the samples stored at $-20^{\circ} \mathrm{C}$ to await assay. 
Assays

Melatonin. The concentration of added melatonin in treatment media was determined by a direct RIA as previousiy described (Webley et al., 1985). This assay has a sensitivity of $8.6 \mathrm{pmol}$ and intra- and inter-assay coefficients of variation of $<6.0 \%$ and $<16 \%$ respectively. In all experiments, the expected concentrations of melatonin were found in the medium after culture with granulosa cells.

Steroids. The concentrations of progesterone and oestradiol were measured by direct RIA kits purchased from RSL Inc. (Carson, CA, U.S.A.) and Sorin Biomedical (Saluggia, Italy) respectively. These assays had working ranges and inter- and intra-assay coefficients of variation as follows: progesterone, $0 \cdot 6-65 \mathrm{pmol} / \mathrm{ml}, 13 \%, 7 \cdot 6 \%$; oestradiol, $0 \cdot 1-2 \cdot 2 \mathrm{pmol} / \mathrm{ml}, 7 \cdot 0 \%, 6 \cdot 0 \%$. The antibodies used in the kits showed no cross-reaction with melatonin.

$D N A$. Cell number was calculated from estimation of DNA concentration according to the relationship $1 \mu \mathrm{g}$ DNA $=1.67 \times 10^{5}$ cells. The bisbenzimide fluorescence method of Labarca \& Paigen (1980) was used, with calf thymus DNA (Sigma) as standard. Diluting the sample from a high concentration, using assay buffer, removed the significant background effect of culture medium.

\section{Statistics}

Steroid concentrations in spent media were normalized for the number of cells present at the start of culture. Progesterone secretion by human and bovine granulosa cells over $24 \mathrm{~h}$ has previously been shown to be linearly related to cell number over a range of at least $1.5 \times 10^{4}$ to $1 \times 10^{6}$ cells per $\mathrm{ml}$ incubation volume (M. R. Luck, unpublished data). The data are expressed as mean \pm s.e.m. and Student's unpaired $t$ test was used to determine statistical significance between control and treatment groups.

\section{Results}

The influence of a range of melatonin concentrations, from 0 to $800 \mathrm{pg} / \mathrm{ml}$, on progesterone and oestradiol secretion by human granulosa cells cultured for 4 days in DMEM is shown in Table 1 . There was no clear dose-response relationship between melatonin and progesterone but progesterone secretion was significantly stimulated by the two highest melatonin concentrations of 200 and $800 \mathrm{pg} / \mathrm{ml}$ whereas melatonin concentrations of $<200 \mathrm{pg} / \mathrm{ml}$ had no consistent effect on progesterone secretion. There was no consistent effect, at any concentration of melatonin, on oestradiol production.

Melatonin concentrations of 20 and $200 \mathrm{pg} / \mathrm{ml}$ were chosen to represent low and high physiological doses. The effects of these two melatonin concentrations on progesterone and oestradiol production by human granulosa cells cultured in RPMI 1640 are shown in Fig. 1. These results may be compared to those from cells exposed to similar doses of melatonin in DMEM, shown in Table 1. There was a difference between the concentrations of progesterone secreted in the two culture media and in the behaviour of the cultures. In RPMI 1640, progesterone secretion in the absence of melatonin declined during the culture period whereas in DMEM progesterone production was greater and increased to a peak on Day 3 of culture. Under both culture conditions, a high physiological concentration of melatonin $(200 \mathrm{pg} / \mathrm{ml})$ significantly stimulated progesterone production, on Days 2 and 3 of culture in RPMI 1640 and Days 1 to 3 in DMEM. Melatonin at a low physiological dose had a small but insignificant stimulatory effect on progesterone secretion and there was no consistent influence, in either culture, on oestradiol production.

These experiments demonstrate the effect of melatonin during continuous exposure. To investigate the influence on progesterone secretion with a period of melatonin exposure similar to that likely to be occurring in vivo during the circadian cycle, media were changed at $8-h$ intervals. Cells 
Table 1. Concentrations of progesterone and oestradiol in culture medium from human granulosa cells cultured in the presence of various concentrations of melatonin

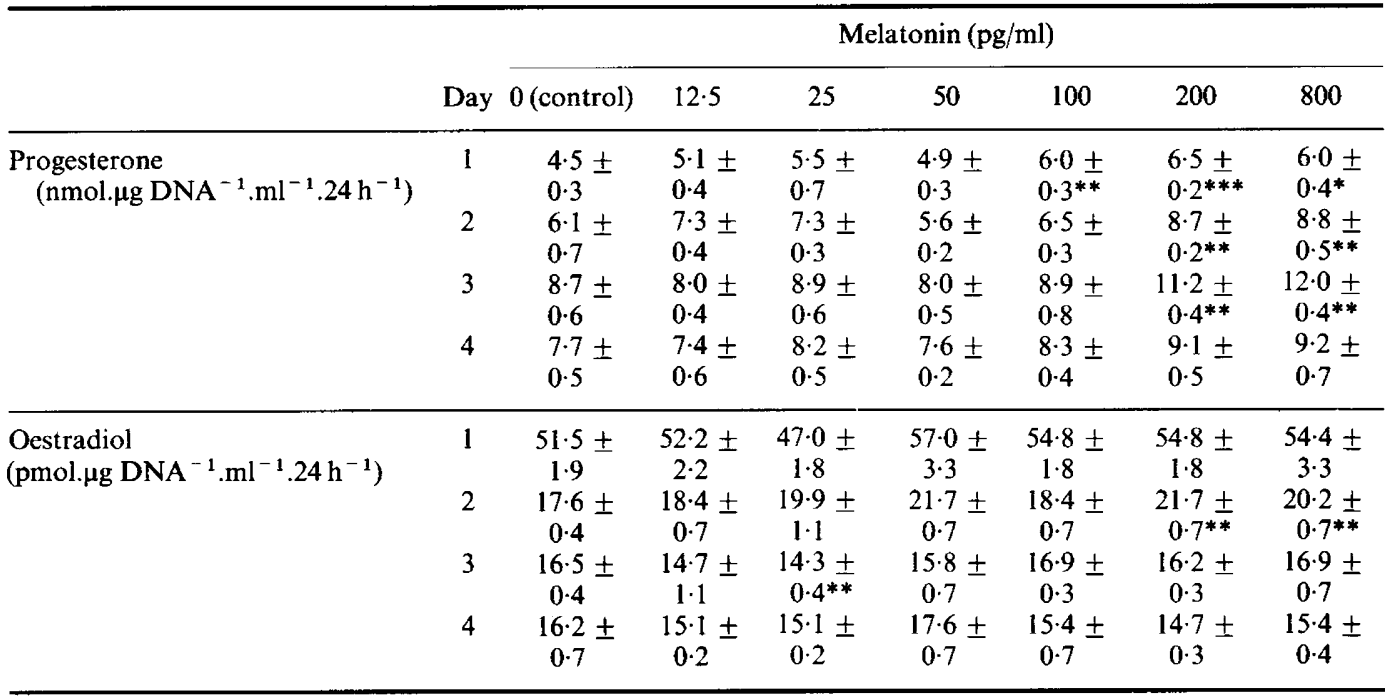

Values are mean \pm s.e.m. for 6 observations.

${ }^{*} P<0.05,{ }^{* *} P<0.01,{ }^{* * *} P<0.001$ compared with control values.
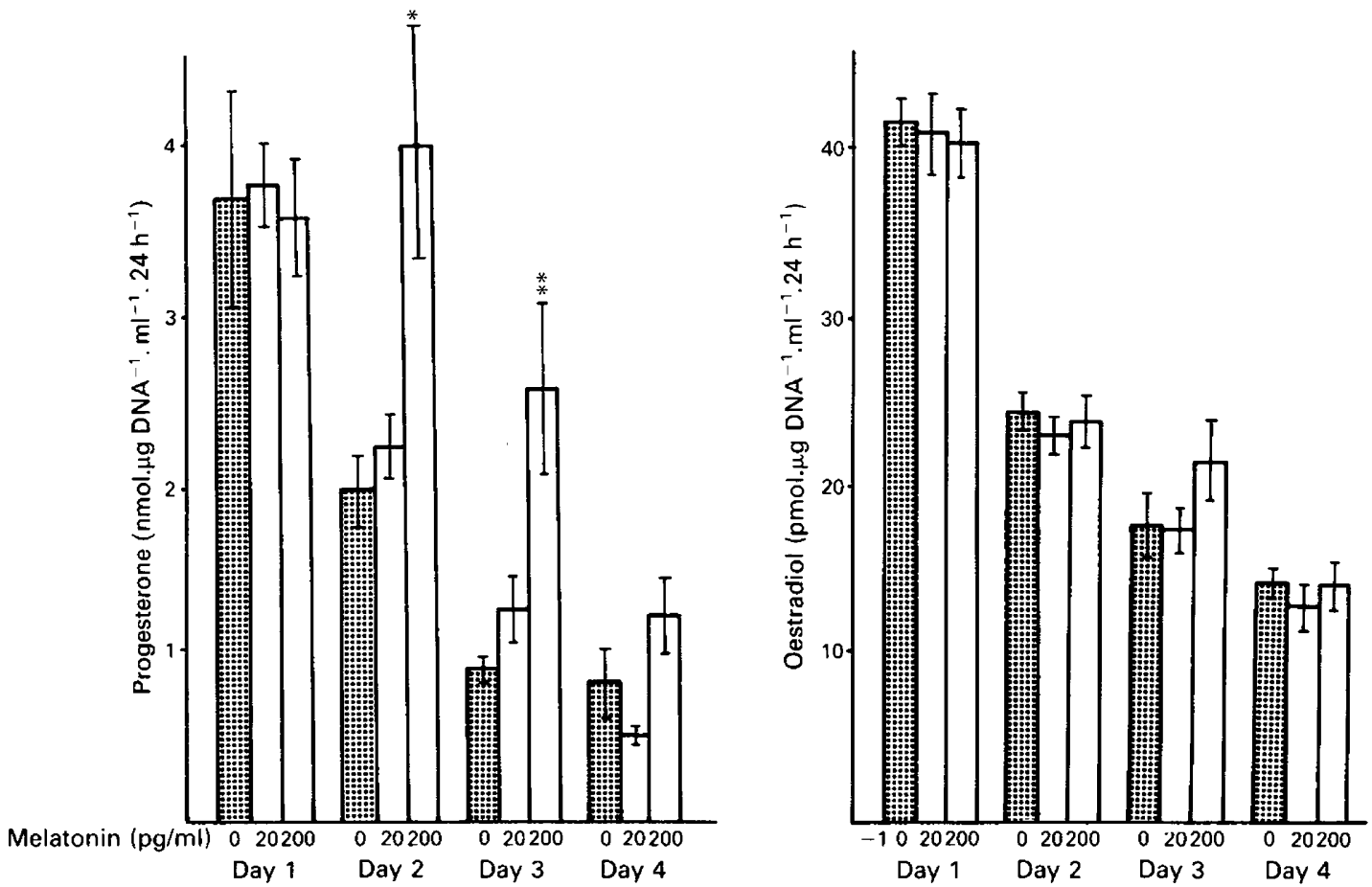

Fig. 1. Concentrations of progesterone and oestradiol produced by human granulosa cells cultured in medium RPM 1640 in the presence of low $(20 \mathrm{pg} / \mathrm{ml})$ and high $(200 \mathrm{pg} / \mathrm{ml})$ physiological concentrations of melatonin. Values are mean \pm s.e.m., $n=6$ replicate wells per treatment. Significance of values compared with control values: ${ }^{*} P<0.05,{ }^{* *} P<0.01$. 


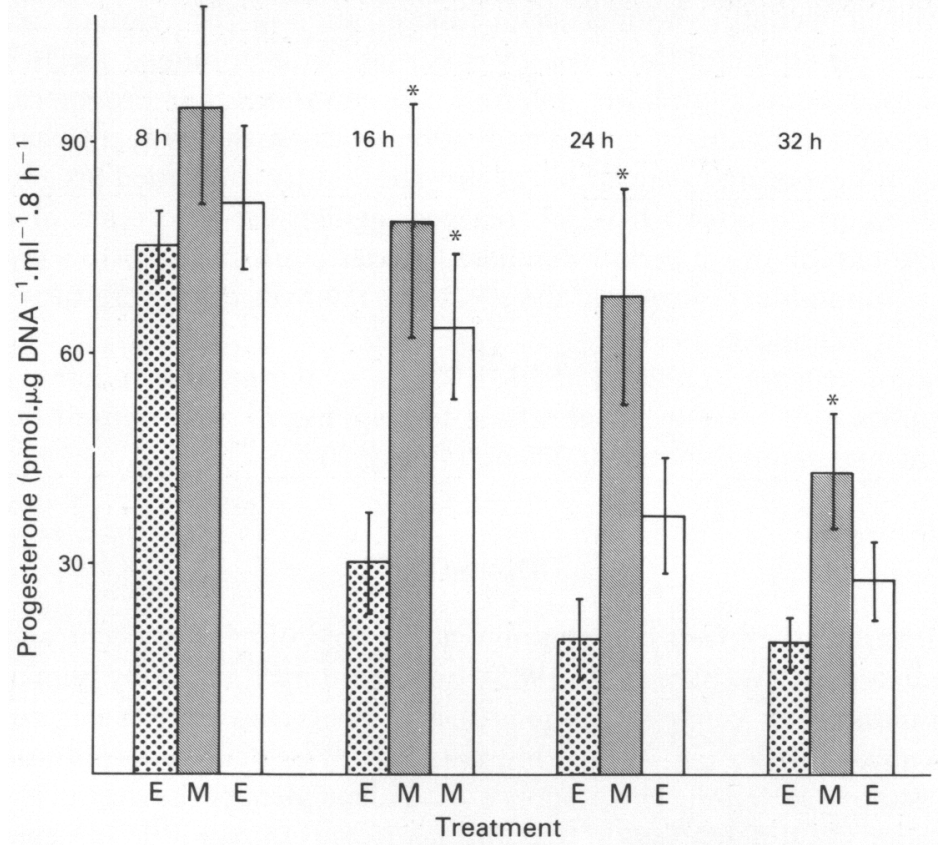

Fig. 2. Progesterone concentrations in culture media from human granulosa cells with changes

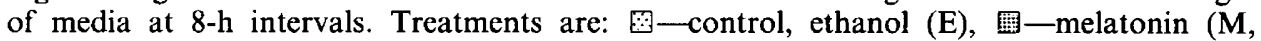
$200 \mathrm{pg} / \mathrm{ml}), \square-$ melatonin during the second 8-h period only. Significance of values compared with control (mean \pm s.e.m.): ${ }^{*} P<0 \cdot 05, n=6$ replicate wells per treatment.

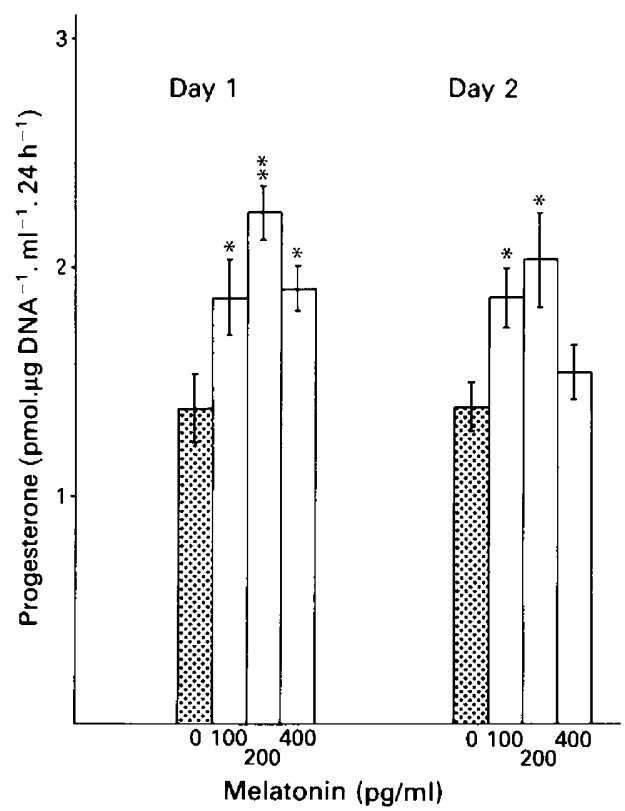

Fig. 3. Progesterone concentrations in culture media from bovine granulosa cells cultured in various concentrations of melatonin. Values are mean \pm s.e.m., $n=6$ replicate wells per treatment. Significance of values compared with control values: ${ }^{*} P<0.05,{ }^{* *} P<0.01$. 
were exposed either to a continuous melatonin concentration of $200 \mathrm{pg} / \mathrm{ml}$ or to an $8-\mathrm{h}$ period of exposure to $200 \mathrm{pg}$ melatonin $/ \mathrm{ml}$ followed by 2 periods with no added melatonin. These cells, cultured in DMEM, produced lower progesterone concentrations than those measured in the previous culture, an overall decline in output probably reflecting the frequent changes in medium. However, continuous exposure to melatonin again significantly stimulated progesterone secretion, a small increase occurring after $8 \mathrm{~h}$ which reached significance after $16 \mathrm{~h}$ of culture (Fig. 2). Exposure to melatonin for an 8 -h period stimulated progesterone secretion to a level similar to that achieved under continuous exposure, and the effect was removed during the subsequent periods in which no melatonin was added.

Bovine granulosa cells were cultured in DMEM in a similar manner to human granulosa cells. There was a significant increase in progesterone in response to melatonin at doses from 100 to $400 \mathrm{pg} / \mathrm{ml}$ with the maximum response at $200 \mathrm{pg} / \mathrm{ml}$ (Fig. 3).

\section{Discussion}

This study has described the effects of melatonin, at the physiological concentrations found in vivo during the circadian cycle (Webley et al., 1985), on steroid production by human granulosa cells which had been induced to secrete luteal quantities of progesterone by being cultured in serumsupplemented medium. Melatonin, at high but not low physiological concentrations, significantly stimulated progesterone secretion. This response was independent of the overall level of cell activity and was seen under the different culture conditions (for example, differing energy content and amino acid composition) associated with different culture media. Although a linear dose-response relationship between melatonin concentration and progesterone secretion was not seen, the results suggest that the stimulation of progesterone secretion is dose-dependent and may start to occur at concentrations likely to be present during the dark phase of the circadian cycle (between 100 and $200 \mathrm{pg} / \mathrm{ml}$ ). The stimulation of progesterone secretion became apparent after $16 \mathrm{~h}$ of culture (see Fig. 2); it occurred with continuous or limited $(8 \mathrm{~h})$ exposure to melatonin and could be reversed by melatonin removal. Taking an exposure period of $8 \mathrm{~h}$ to represent that experienced during the night-time elevation of the circadian cycle, this cycle of treatment suggests that stimulation of progesterone secretion can occur under physiological conditions in terms of both the concentration of melatonin and the period of exposure.

The cow shows a nocturnal rise in melatonin secretion of similar magnitude to that seen in humans (Martin et al., 1983). Our observation of a stimulation of progesterone secretion by bovine granulosa cells treated with less than $1 \mathrm{nmol}$ melatonin therefore shows that the effectiveness of physiological concentrations is not specific to human cells. The lack of response of bovine midluteal cells to higher concentrations of melatonin $\left(10^{-5}\right.$ to $\left.10^{-7} \mathrm{M}\right)$, reported by Battista \& Condon (1986), may reflect the short period of exposure used. Alternatively, responsiveness may be confined to granulosa or granulosa-derived cells and is therefore lost or reduced by the mid-luteal phase (Schwall \& Niswender, 1985).

Our observation of a stimulation of progesterone secretion but not of oestradiol secretion in human cells is consistent with that observed in the rat (Fiske et al., 1984). The lack of aromatase stimulation was not the result of substrate limitation since male serum was used to supplement the cultures and would have provided androgen. A granulosa cell stimulation confined to the progesterone compartment therefore suggests a number of possible mechanisms for melatonin action, including either a change in the rate of uptake of lipoprotein-bound cholesterol from serum, a change in the rate of intracellular lipoprotein catabolism and conversion of cholesterol to progesterone, or a change in the rate of de-novo synthesis of progesterone from acetate. MacPhee et al. (1975) described the stimulation of progesterone production by human corpus luteum slices, with pharmacological doses of melatonin and observed an increase in the incorporation of labelled acetate into progesterone. It therefore appears that melatonin may be able to influence de-novo 
synthesis but does not exclude the possibility that it also has a direct effect on cholesterol metabolism. It is also possible that the responsiveness of granulosa cells to melatonin may be potentiated by gonadotrophins, as reported for the rat by Fiske et al. (1984). In a previous investigation of the circadian pattern of melatonin during the human menstrual cycle (Webley \& Leidenberger, 1986), a significant increase in the circadian melatonin output was observed during the luteal phase of the cycle. Higher melatonin concentrations were also recorded in subjects taking exogenous progestagens in the form of the contraceptive pill. These studies, together with the present results, indicate a positive relationship between melatonin and progesterone. Melatonin, via its direct action on the ovary, may increase the output of progesterone which in turn feeds back on the pineal gland to increase melatonin secretion. A change in the circadian pattern of progesterone secretion has not been reported in man but a nocturnal increase in secretion has been described for the rhesus monkey (Spies et al., 1974; Healy et al., 1984). A mutual reinforcement between the two hormones may provide a mechanism through which the pineal gland could influence menstrual cyclicity.

We thank Bettina Bartlick and Hildegard Mehl for technical assistance, Vera Baukloh for providing human tissue derived from IVF procedures and Professor F. Leidenberger for his encouragement and support. This study was supported in part by grant $0706506 / 9$ from the Bundesministerium für Forschung und Technologie.

\section{References}

Battista, P.J. \& Condon, W.A. (1986) Serotonin-induced stimulation of progesterone production by cow luteal cells in vitro. J. Reprod. Fert. 76, 231-238.

Cardinali, D.P. (1981) Melatonin: a mammalian pineal hormone. Endocr. Rev. 2, 327-346.

Cardinali, D.P., Hyyppa, M.T. \& Wurtman, R.J. (1973) Fate of intracisternally injected melatonin in the rat brain. Neuroendocrinology 12, 30-40.

Cardinali, D.P., Vacas, M.I. \& Estevez, E. (1979) Specific binding of melatonin in the rat brain. Endocrinology 105, 437-441.

Cohen, M., Roselle, D., Chabner, B., Schmidt, T.J. \& Lippman, M. (1978) Evidence for a cytoplasmic melatonin receptor. Nature, Lond. 274, 894-895.

Ellis, L.C. (1972) Inhibition of rat testicular androgen synthesis in vitro by melatonin and serotonin. Endocrinology 90, 17-28.

Fiske, V.M., Parker, K.L., Ulmer, R.A., Hoon, Ow, C. \& Aziz, N. (1984) Effect of melatonin alone or in combination with human chorionic gonadotropin or ovine luteinizing hormone on the in vitro secretion of estrogens or progesterone by granulosa cells of rats. Endocrinology 114, 407-410.

Healy, D.L., Schenken, R.S., Lynch, A., Williams, R.F. \& Hodgen, G.D. (1984) Pulsatile progesterone secretion: its relevance to clinical evaluation of corpus luteum function. Fert. Steril. 41, 114-121.

Jungclas, B. \& Luck, M.R. (1986) Evidence for granulosa-theca interaction in the secretion of oxytocin by bovine ovarian tissue. J. Endocr. 109, R1-R4.

Kano, T. \& Miyachi, Y. (1976) Direct action of melatonin on testosterone and cyclic GMP production using rat testis tissue in vitro. Biochem. biophys. Res. Commun. 72, 969-975.

Labarca, C. \& Paigen, K. (1980) A simple, rapid and sensitive DNA procedure. Analyt. Biochem. 102, $344-352$.
MacPhee, A.A., Cole, F.E. \& Rice, B.F. (1975) The effect of melatonin on steroidogenesis by the human ovary in vitro. J. clin. Endocr. Metab. 40, 688-696.

Martin, T.C., Cunningham, N.F. \& Saba, N. (1983) Estimation of melatonin in bovine plasma: patterns in Jersey heifers treated with cloprostenol at two times of day. J. Endocr. 98, 189-196.

Niles, L.P., Wong, Y.W., Mishra, R.K. \& Brown, G.M. (1979) Melatonin receptors in brain. Eur. J. Pharmac. 55, 219-220.

Peat, F. \& Kinson, G.A. (1971) Testicular steroidogenesis in vitro in the rat in response to blinding, pinealectomy and to the addition of melatonin. Steroids 17, $251-263$.

Schwall, R.H. \& Niswender, G.D. (1985) Two types of steroidogenic cells in the ewe: morphological and biochemical characteristics. In Implantation of the Human Embryo, pp. 31-38. Eds R. G. Edwards, J. M. Purdy \& P. C. Steptoe. Academic Press, London.

Spies, H.G., Mahoney, C.J., Norman, R.L., Clifton, D.K. \& Resko, J.A. (1974) Evidence for a diurnal rhythm in ovarian steroid secretion in the Rhesus monkey. $J$. clin. Endocr. Metab. 39, 347-351.

Webley, G.E. \& Leidenberger, F. (1986) The circadian pattern of melatonin and its positive relationship with progesterone in women. J. clin. Endocr. Metab. 63, 323-328.

Webley, G.E., Mehl, H. \& Willey, K.P. (1985) Validation of a sensitive direct assay for melatonin for investigation of circadian rhythms in different species. $J$. Endocr. 106, 387-394.

Wurtman, R.J., Axelrod, J. \& Potter, L.T. (1964) The uptake of $\mathrm{H} 3$ melatonin in endocrine and nervous tissues and the effects of constant light exposure. $J$. Pharmacol. exp. Ther. 143, 314-318.

Received 28 April 1986 